anales de psicología / annals of psychology

2019, vol. 35, nº 2 (may), 195-203

http://dx.doi.org/10.6018/analesps.35.2.304501
(C) Copyright 2019: Editum. Servicio de Publicaciones de la Universidad de Murcia. Murcia (Spain) ISSN print edition: 0212-9728. ISSN on line edition (http://revistas.um.es/analesps): 1695-2294.

On line edition License Creative Commons 4.0: BY-NC-ND

\title{
Evaluation of early life experiences: The ELES scale and its clinical use
}

\author{
María de Gracia León-Palacios ${ }^{1}$, Miguel Garrido-Fernández¹, Cristina Senín-Calderón², Salvador Perona-Garcelán, \\ Paul Gilbert ${ }^{3}$, and Juan Francisco Rodríguez-Testal ${ }^{1, *}$ \\ 1 Personality, Evaluation and Psychological Treatment Department, University of Seville (Spain) \\ 2 Department of Psychology, University of Cadiz (Spain) \\ 3 Mental Health Research Unit, Kingsway House, Kingsway Hospital, Derby (UK)
}

\begin{abstract}
Título: Evaluación de las experiencias vitales tempranas: la escala ELES y su uso clínico.

Resumen: Antecedentes: la escala de Experiencias Vitales Tempranas (ELES) evalúa el recuerdo de la amenaza y subordinación percibidas durante la infancia en las relaciones familiares partiendo de la teoría del rango social. Se propone adaptar al español dicha escala y comprobar su estructura factorial mediante una validación cruzada y explorar sus propiedades psicométricas. Método: participaron 960 sujetos (863 de población general y 97 pacientes). Resultados: los datos confirman la estructura factorial de la versión inicial de Gilbert, Cheung, Grandfield, Campey, y Irons (2003), obteniendo tres factores: sumisión, amenaza, y desvalorización, explicando un $66.31 \%$ de la varianza. La versión española de la escala ELES resultó estar compuesta por el mismo número de ítems que la original y mostró índices adecuados de validez, consistencia interna, fiabilidad retest, fiabilidad compuesta e invarianza por género. Conclusiones: la escala de Experiencias Vitales Tempranas (ELES) puede ser de utilidad para evaluar las experiencias vitales tempranas, estudiar la relación entre dichas experiencias en diferentes manifestaciones psicopatológicas y establecer posibles modelos explicativos.

Palabras clave: experiencias vitales; sumisión; amenaza; desvalorización; escala ELES; validación cruzada.
\end{abstract}

\section{Introduction}

Early relationships with parents and their influence on the development of psychopathology has been a subject of interest from different theoretical approaches. Traditionally, the focus has been on analysis of attachment relationships, based on the theory proposed by John Bowlby. In this theory, the creation of emotional ties functions as the basis of evolutionary development and serves as the model of social behavior which is maintained throughout life, as reflected in biological, cognitive and socio-emotional development of the human being (Bowlby, 1980). In recent years, there has been growing interest in studying this attachment and the development of psychopathology in youth and adults (Paetzold, Rholes, \& Kohn, 2015), and for example, whether the style of attachment prior to treatment is associated with clinical and functional changes in persons with mental states at high risk of psychosis (Quijada, Kwapil, Tizón, Sheinbaum, \& Barrantes-Vidal, 2015). Among the mental disorders related to impairment of attachment are personality, anxiety, depressive and posttraumatic stress disorders, psychotic, and eating behavior disorders (Gumley, Taylor, Schwannauer, \& MacBeth, 2014; Wickham, Sitko, \& Bentall, 2015).

* Correspondence address [Dirección para correspondencia]

Juan F. Rodríguez-Testal. Personality, Evaluation and Psychological Treatment Department, University of Seville. St. Camilo José Cela s/n, 41018 Seville (Spain). E-mail: testal@us.es

(Article received: 17-09-2017; revised: 18-03-2018; accepted: 09-04-2018)
Abstract: Background: The Early Life Experiences Scale (ELES) evaluates the memory of threat and subordination perceived in childhood family relationships based on social rank theory. This scale was adapted to Spanish, its factor structure was tested by cross-validation, and its psychometric properties were explored. Method: 960 subjects participated $(863$ subjects from the general population and 97 patients). Results: Data confirm the factor structure of the original version by Gilbert, Cheung, Grandfield, Campey, and Irons (2003), obtaining a similar model with three factors: submission, threat, and devaluation, which explained $66.31 \%$ of the variance. The Spanish version of the ELES was comprised of the same number of items as in the original study and showed adequate indices of validity, internal consistency, retest and combined reliability, and invariance by gender. Conclusions: The Early Life Experiences Scale (ELES) can be a useful measure for evaluating early life experiences. Its application may be very relevant in studying the relationship between these experiences and psychopathological manifestations in constructing explanatory models.

Keywords: life experiences; submission; threat; devaluation; ELES scale; cross validation.

Stevens and Price (2000) believe this responds to the basic need for attachment. However, there is another basic need which has to do with status (respect or validation) in interpersonal relationships established with caregivers. Some authors base this on the Social Rank Theory (Gilbert, 2001a; Gilbert, Allan, Brough, Melley, \& Miles, 2002). This theory suggests that relations between caregivers and their children are based on power relationships (dominance versus submission), in which a person's evaluations of own rank or status (incompetence versus competence) intervene.

Therefore, another way of studying early experiences is based not so much on the attachment system molded by experiences and behavior of caregivers as by the memory of feelings and behaviors of the person under study related to the behavior of their caregivers. While the attachment theory tends to concentrate on the need for closeness and security from the figures of attachment in difficult situations, the social rank theory concentrates more on establishing relationships of control and domination by the caregivers (Gilbert et al., 2001) and valuing competence or capability of the one evaluated, causing feelings of threat (loss of rank) and submission in the children. Thus children who are afraid of their parents and have the feeling of being subordinate may lead to defensive behavior, for example, submissive, thereby achieving control of parental hostility or control (Lopes \& Pinto-Gouveia, 2013). Submissive behavior based on fear is associated with inhibition of assertive behavior (Gilbert et al., 2002). Furthermore, children who tend to pay too much at- 
tention to threats (instead of trusting their parents as a secure basis for emotional regulation) may be more vulnerable to depression (Gilbert et al., 2002). Therefore, early negative experiences could cultivate insecure attachment styles and difficulties in trusting in others (Cruddas, Gilbert, \& McEwan, 2012), but what causes sensitivity to various disorders is the stress of rejection and/or hostility by caregivers. This means the person takes on a defensive response to stress (by being forced into an undesired subordinate position), the physiological process involved and sustained over time, and self-other schema (e.g., seeing oneself as inferior) (Gilbert, Cheung, Grandfield, Campey, \& Irons, 2003).

In brief, children may grow up in environments where they feel afraid and undergo stress responses, anxiety and depressive states, and develop attentional biases toward threatening stimuli causing chronic effects due to maintenance of physiological responses to altered mood (Gilbert, 2001b; 2001c). This in turn may influence development of schemas about themselves which are activated in interpersonal relationships (e.g., feeling inferior to others may lead to generalized behavior based on submission). This style based on submission and subordination has been related to the development of depression, social anxiety, shame, cognitive rumination (Cheung, Gilbert, \& Irons, 2004; Gilbert, 2000), paranoia (Lopes \& Pinto-Gouveia, 2013; Pinto-Gouveia, Matos, Castilho, \& Xavier, 2014), hallucinations (Birchwood, Meaden, Trower, Gilbert, \& Plaistow, 2000), or eating disorders (Cardi, Di Matteo, Gilbert, \& Treasure, 2014; Duarte et al., 2017).

More specifically, paranoid ideation is related directly to external shame and indirectly to internal shame of submission based on early negative experiences. In depression, internalization of experiences of shame, threat and submission in the belief that one is unattractive and worthless in the eyes of others, is what makes one vulnerable to the disorder (Pinto-Gouveia et al., 2014). In unipolar depression, in addition to submission and shame (Cheung et al., 2004), inhibited and intrapunitive anger has been characterized, as in bipolar depression, but in unipolar depression it is specifically extrapunitive anger (Allan \& Gilbert, 2002). In bipolar disorder, variations in social rank have been observed to be related to changes in humor (Gilbert, McEwan, Hay, Irons, \& Cheung, 2007). In studies of hallucinations, subordination to voices becomes relevant to their onset and origin (Paulik, 2012). In brief, in schizophrenia with voices and in depression, subordination takes place as a defense against one's own thoughts of self-contempt (Gilbert et al., 2001).

The role of threat and submission has been emphasized. However, not all perception of subordination and submissive behavior implies a disorder in itself. It has been suggested that social defeat and the impossibility of running away or escaping (entrapment) are conditions clearly related to the anhedonia which characterizes depression (Gilbert et al., 2002; Gilbert \& Allan, 1998), schizophrenia (Gilbert, 2000), and persons at risk of psychosis (Valmaggia et al., 2015).

Reliable, validated scales have been constructed for sci- entific studies dealing with evaluation of memories of feelings about parental relationships. Gilbert developed the Early Life Experiences Scale (ELES) (Gilbert et al., 2003), which evaluates the memory of perceived threat and subordination in childhood family relationships. This evaluation tool may be very useful for the study of psychopathological manifestations enabling explanatory models to be constructed for the study of the relationship of these early experiences with formation of the attachment system and expressed emotion, as well as related emotional states. It has recently been adapted to Portuguese and validated for use with an adolescent population (Pinto-Gouveia, Xavier, \& Cunha, 2016), validated with university students in the Turkish version (Akin, Uysal, \& Çitemel, 2013), and some studies have attempted to analyze the relationship between early life experiences and selfcompassion (Satici, Uysal, \& Akin, 2015).

The goals of this study were to adapt the Early Life Experiences Scale (ELES) to Spanish, test the scale's structure using cross-validation and explore its psychometric properties in an instrument related to social rank theory and memories of threat and subordination perceived during childhood. The importance of studying threat and submission is that they are relevant conditions for vulnerability to developing and maintaining psychopathological alterations, as well as essential to follow during intervention related to a person's early experiences and how they rank themselves and defend themselves from them (Gilbert et al., 2002).

We expected to find adequate validity of the construct based on the original model with a factor structure similar to the original version (Gilbert et al., 2003) comprised of the three factors: submission, threat, and devaluation. We also expected these factors to be significantly associated with instruments measuring the anxiety, depression and somatic preoccupation components found, and therefore, significant convergent and discriminant validity, finding reliability indicators, as well as the adequate sensitivity and specificity for this early life experiences scale.

\section{Method}

\section{Participants}

The sample in this study was made up of a total of 960 participants (863 from the general population -PG- and 97 patients). The patients were from public and private mental health centers recruited during one natural year. $62.9 \%$ were women. Their ages varied from 19 to 65 years $(M=34.84$ $S D=11.86)$. The average Social Class Index (SCI) (Hollingshead, 1975) was 37.9 (mean social class) (ranges: 11 - 17, very high SCI; 18 - 27, high SCI; 28 - 43, middle SCI; $44-60$, low SCI; 61 - 77, very low SCI). Patient diagnoses were made in clinical interview format by specialized professionals with over 20 years of clinical experience following DSM-IV-TR (American Psychiatric Association, 2000) criteria, and classified as: Depressive disorders $(n=14)$, adjustment disorderas $(n=6)$, dissociative disorders $(n=1)$, anxie- 
ty disorders $(n=25)$, schizophrenia and other psychotic disorders $(n=19)$, eating disorders $(n=3)$, bipolar disorders $(n$ $=10)$, somatoform disorders $(n=11)$ and other Axis I categories of disorders $(n=8)$.

The PG group was made up of university students recruited by accessibility and non-university students were recruited by snowball sampling. $79.1 \%$ were women aged 18 to 59 years $(M=23.03 ; S D=6.55)$. Their average SCI was 54.42 (low social class). All subjects who expressly stated that they had some psychopathology at the time of evaluation or were taking medication were eliminated from the sample. The overall sample was divided into two halves at random (SPSS ver. 22) (half $1=435$ participants in PG and 45 patients; half $2=428$ PG subjects and 52 patients) for cross validation. Both groups were equivalent in gender $\left(\chi^{2}(960)=\right.$ $0.597, p=.440)$, marital status $\left(\chi^{2}(960)=1.98, p=.576\right)$, age $(t(960)=0.531, p=.093)$ and SCI $(t(228)=.773, p=.416)$ (see Table 1).

Table 1. Sociodemographic characteristics of participants.

\begin{tabular}{|c|c|c|c|c|c|c|c|c|c|c|c|c|}
\hline & \multicolumn{4}{|c|}{$\begin{array}{c}\text { Total sample } \\
\text { N: } 960\end{array}$} & \multicolumn{4}{|c|}{$\begin{array}{c}\text { EFA sample } \\
\quad N: 480\end{array}$} & \multicolumn{4}{|c|}{$\begin{array}{c}\text { CFA sample } \\
N: 480\end{array}$} \\
\hline & $n$ & $\%$ & $M$ & $S D$ & $n$ & $\%$ & $M$ & $S D$ & $n$ & $\%$ & $M$ & $S D$ \\
\hline \multicolumn{13}{|l|}{ Gender } \\
\hline Male & 216 & 22.5 & & & 113 & 23.5 & & & 103 & 21.5 & & \\
\hline Female & 744 & 77.5 & & & 367 & 76.5 & & & 377 & 78.5 & & \\
\hline Age & & & 24.22 & 8.08 & & & 24.08 & 7.83 & & & 24.36 & 8.33 \\
\hline \multicolumn{13}{|l|}{ Marital status } \\
\hline single & 844 & 87.9 & & & 427 & 89.0 & & & 417 & 86.9 & & \\
\hline married/partner & 101 & 10.5 & & & 45 & 9.4 & & & 56 & 11.7 & & \\
\hline widowed & 3 & 0.3 & & & 1 & 0.2 & & & 2 & 0.4 & & \\
\hline separated/divorced & 12 & 1.3 & & & 7 & 1.5 & & & 5 & 1.0 & & \\
\hline Social Class Index & & & 48.19 & 22.91 & & & 46.98 & 23.29 & & & 49.33 & 22.60 \\
\hline \multicolumn{13}{|l|}{ Group } \\
\hline Patients & 97 & 10.1 & & & 45 & 9.4 & & & 52 & 10.8 & & \\
\hline Controls & 863 & 89.9 & & & 435 & 90.6 & & & 428 & 89.2 & & \\
\hline
\end{tabular}

\section{Instruments}

Early Life Experiences Scale, (ELES) (Gilbert et al., 2003): Test evaluating the memory of threat and subordination perceived in childhood family relationships. The scale consists of 15 items and contains three main factors: threat (e.g.: "The atmosphere at home could suddenly become threatening for no obvious reason"), submission (e.g.: "I felt on edge because I was unsure if my parents might get angry with me"), and devaluation (e.g.: "I felt able to assert myself in my family"). The items are scored on a Likert-type scale of 1 (completely false) to 5 (completely true). The scale has adequate internal consistency for its three factors in the original study: threat $(\alpha=.89)$, submission $(\alpha=.85)$ and devaluation $(\alpha=$ .71).

First self-reported evaluation (tool developed by authors). Identifies the social class index (SCI) (Hollingshead, 1975), current illnesses, psychopathological background, history and duration of symptoms, psychopharmacological treatments and use of drugs.

General Health Questionnaire, GHQ-28, (Goldberg, 1996). This is a brief form of the original 93-item Goldberg scale for Spanish validation. It is a screening test which evaluates general health and social dysfunction. It consists of 28 items grouped in four subscales on somatic symptoms, anxiety and insomnia, social dysfunction and severe depression. It has adequate reliability properties (test-retest, .90) and validity (sensitivity from $44 \%$ to $100 \%$ and specificity from $74 \%$ to $93 \%$ ). For this study, three symptom subscales were used with the overall sample: somatic $(\alpha=.78)$, anxiety $(\alpha=.82)$ and depressive $(\alpha=.77)$ symptoms.

Hospital Anxiety and Depression Scale, (HADS) (Zigmond \& Snaith, 1983). This 14-item questionnaire evaluates anxiety (odd items) and depressive (even items) symptomatology, seven items in each part, on a Likert-type scale of $0-3$ points according to the symptoms during the past week. The Spanish version by Tejero, Guimera, Farré, and Peri (1986) had a total internal consistency of $\alpha=.86, \alpha=.83$ for anxiety, and $\alpha=.87$ for depression. In this study overall internal consistency was $\alpha=.84, \alpha=.78$ for anxiety, and $\alpha=.71$ for depression, considering the whole sample.

\section{Procedure}

First, permission for translation and adaptation of this scale was requested of the author, Paul Gilbert. Adaptation and translation to Spanish of the ELES was done by bilingual experts following the method of reverse translation and considering the guidelines of the International Test Commission (Muñiz, Elosua, \& Hambleton, 2013). The participants were informed of the purposes of the study and before applying the tests, they were asked for their written informed consent, after which their clinical and demographic information was acquired, and then the measurement instruments were administered. The study was authorized by the Ethics Committee and the ethical principles for medical research involving human subjects proposed by the World Medical 
Association in the Helsinki Declaration (World Medical Association, 2013) were guaranteed.

Data were analyzed using the SPSS 22 and LISREL 8.7 programs. Descriptive analyses of the sociodemographic variables and comparisons of means of participants in the two random groups formed were performed for ELES crossvalidation. Frequency, skewness and kurtosis analyses were done for each item response. Internal consistency of the complete ELES and of the three factors proposed by Gilbert et al. (2003) was tested to evaluate the suitability of the original structure. As the main analysis for establishing the validity of the construct, first an Exploratory Factor Analysis (EFA) was done using the Robust Maximun Likelihood (RML) extraction method and a Direct Oblimin rotation on the first half of the sample. The multivariate normality was tested using the Mardia test. Then a Confirmatory Factor Analysis (CFA) using the RML procedure and the asymptotic covariance matrix was done to test the hypothesized model with the second half of the sample. The Chi-squared, NonNormed Fit Index (NNFI), Goodness of Fit Index (GFI), and Comparative Fit Index (CFI) which must be $>.90$ (Baumgartner \& Homburg, 1996) were used to test the overall fit of models. In addition to these indices, the Root Mean Square Error of Approximation (RMSEA) and its confidence interval at $90 \%$, which must be $<.06$ for a good fit, as well as the Standardized Root Mean Square Residual (SRMR), which has to be $<.08$ (Hu \& Bentler, 1999), were also calculated. Multi-group CFA were performed to test the measurement invariance of the ELES scale across gender with AMOS 22 software. Model fit was evaluated considering the $\triangle \mathrm{CFI}$ and $\triangle \mathrm{RMSEA}$. Invariance exists if the $\Delta$ in the CFI and RMSEA is low (usually accepted $\Delta<.01$, Cheung \& Rensvold, 2002).

The Pearson's correlation coefficient of ELES scores, GHQ-28 factors, and HADS factors was used to study convergent validity. For discriminant validity, the confidence interval of the correlations between the ELES factors was calculated based on their covariance and error (Anderson \& Gerbing, 1988). With the final structure of the ELES established, internal consistency was tested using the ordinal alpha given the characteristics of the response system (Elosua \& Zumbo, 2008), and for test-retest reliability, the Pearson correlation coefficient $(r)$ was used. The indicators of Combined Reliability (CR), Average Variance Extracted and Maximum Shared Squared Variance (MSV) are provided. Finally, the Receiver Operating Characteristic Curve (ROC) was analyzed considering the significance of the area under the curve, the confidence interval and establishing the sensitivity and specificity for the overall ELES score and patient/control criterion.

\section{Results}

\section{Descriptive Analysis of ELES items}

Skewness and kurtosis varied from 0.23 to 2.20 and from -0.29 to 4.08 , respectively, following the factors in the English version of the scale. Item 13 of the threat factor had the most skewness and kurtosis. These results show that fit of the scores on these factors is adequate in absolute values since they are below 2 for skewness and 7 for kurtosis (Curran, West, \& Finch, 1996).

\section{Construct validity}

Exploratory Factor Analysis of the ELES

An EFA was done with the first half of the simple. The Mardia test result was $46.70(p<.001)$. Parallel analysis and eigenvalue recommended a three-factor solution. The result showed adequate values for the Kaiser-Meyer-Olkin test $(K M O=.93)$ and Bartlett's statistic $=3472.1(d f=105 ; p<$ $.001)$. This solution explains $63.57 \%$ of the variance. The factors are similar to those found by Gilbert et al. (2003), so they have the same names as in the original version of the scale.

Table 2 shows the factor solution found. The first factor explained the highest percentage of variance (46.3\%), and corresponds in large part to the original "submission" factor, except for Item 4, which in Gilbert's original saturates on the threat factor. The second factor groups all of the items in the original "devaluation" factor. The third factor groups the same items in the "threat" factor. The correlations between factors vary from .541 to .607 . The goodness of fit indicators were adequate $\mathrm{CFI}=.983, \mathrm{NNFI}=.97, \mathrm{GFI}=.99, \mathrm{RMSEA}$ $=.072(95 \% \mathrm{CI}=.068-.080), \mathrm{RMSR}=.027(95 \% \mathrm{CI}=.026-$ $.026)$.

Table 2. Structure matrix from Exploratory Factor Analysis.

\begin{tabular}{lccc}
\hline \multirow{2}{*}{ Items } & Factor & Factor Factor \\
& I & II & III \\
\hline 1. I often had to give in to others at home. & .797 & & \\
5. If I didn't do what others wanted I felt I & .635 & & \\
$\quad$ would be rejected. & & & \\
2. I felt on edge because I was unsure if my & .593 & \\
parents might get angry with me. & & \\
12. I often had to go along with others even & .581 & & \\
$\quad$ when I did not want to. & & & \\
4. There was little I could do to control my & .519 & \\
$\quad$ parents' anger once they became angry. & & & \\
3. I rarely felt my opinions mattered much. & .501 & & \\
10. I often felt subordinate in my family. & .375 & & \\
7. I felt very comfortable and relaxed around & & .748 & \\
my parents. & & .678 & \\
9. I felt an equal member of my family. & & .624 & \\
6. I felt able to assert myself in my family. & & \\
13. In order to avoid getting hurt I used to & & .798 \\
try to avoid my parents. & & & \\
8. My parents could hurt me if I did not be- & & & .787 \\
have in the way they wanted. & & & \\
\hline
\end{tabular}




\begin{tabular}{lccc}
\hline Items & Factor & Factor & Factor \\
& I & II & III \\
\hline $\begin{array}{l}\text { 14. The atmosphere at home could suddenly } \\
\text { become threatening for no obvious rea- }\end{array}$ & &. & .604 \\
$\quad$ son. & & \\
15. I experienced my parents as powerful & & .594 \\
$\quad$ and overwhelming. & & \\
11. My parents exerted control by threats & & .573 \\
$\quad$ and punishments. & - & \\
FI & .541 & & \\
F II & .607 & .566 & \\
F III &
\end{tabular}

Note: The bottom part of the table corresponds to the correlations between the factors (FI: submission; FII: devaluation; FIII: threat).

\section{Confirmatory Factor Analysis of the ELES}

To test the suitability of the EFA structure, a CFA was done with the second group of participants. The 15 items on the ELES fit to the three-factor model with the following goodness of fit indicators: Satorra Bentler Scaled $\chi^{2}(87)=$ 183.44, $p<.001 ; N N F I=.99$, GFI $=.88$, CFI $=.99$, RMSE $A=.048$ (95\% CI $=.038-.058), S R M R=.047$. The final model containing the same number of items as the one by Gilbert et al. (2003) consisted of seven items for the "submission" dimension $(4,12,1,5,3,2,10)$, five items for the "threat" dimension $(13,14,15,11$ y 8$)$ and three for "devaluation" $(6,7,9)$. Item 4 on Gilbert's original scale remained in the submission factor as no change was suggested by the modification indices. Figure 1 shows the CFA with standardized factor weights.

A factorial invariance test was carried out across gender. The gender invariance test showed that the configural invariance model across gender demonstrated acceptable model fit. The results of metric invariance analyses suggest that the item scores can be meaningfully compared across gender. The scalar invariance revealed that when constraining item weights and intercepts, there is invariance across men and women. The findings of this test showed that the model fits the data well (Table 3).

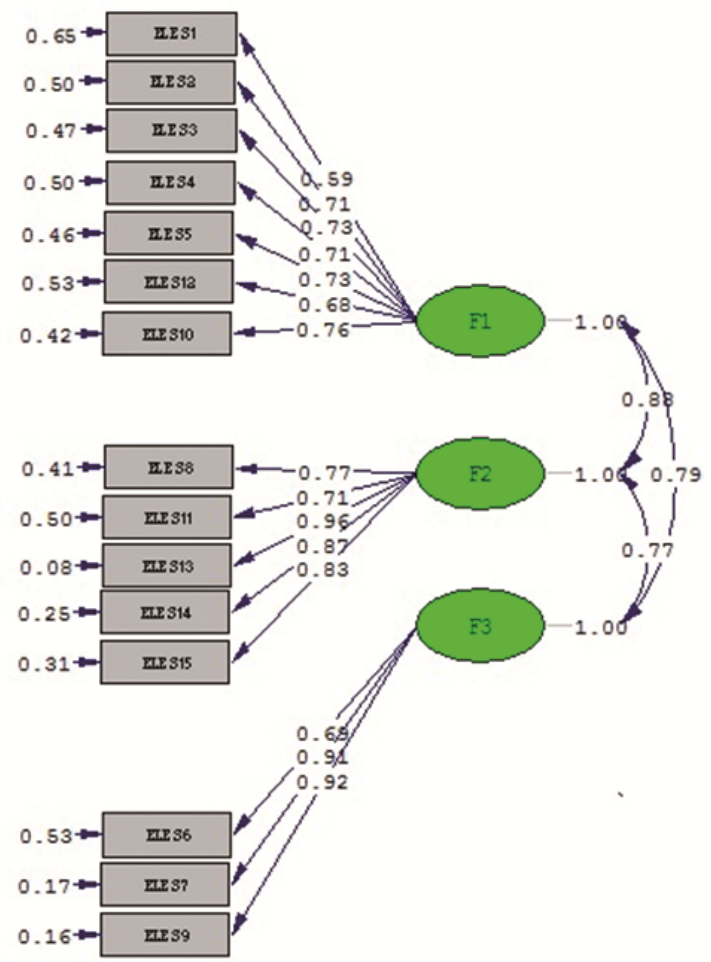

Chi-Square $=177.67, \mathrm{df}=87, \mathrm{P}$-value $=0.00000, \mathrm{RMSEA}=0.047$

Figure 1. Model resulting from Confirmatory Factor Analysis (FI: submission; F2: threat; F3: devaluation).

Table 3. Goodness of fit statistics for tests of measurement invariance of the ELES scale across gender

\begin{tabular}{|c|c|c|c|c|c|c|}
\hline Gender & $\chi^{2}$ & $d f$ & CFI & RMSEA $(90 \% \mathrm{CI})$ & $\Delta \mathrm{CFI}$ & $\triangle \mathrm{RMSEA}$ \\
\hline Configural invariance $^{1}$ & 621.22 & 176 & .934 & $.051[.047, .056]$ & $\mathrm{N} / \mathrm{A}$ & $\mathrm{N} / \mathrm{A}$ \\
\hline Metric invariance $^{2}$ & 628.79 & 186 & .935 & $.050[.046, .054]$ & .001 & .001 \\
\hline Scalar invariance $^{3}$ & 644.44 & 201 & .935 & $.048[.044, .052]$ & .000 & .002 \\
\hline
\end{tabular}

Note. 1 Unconstrained model; 2 Equality of factor loading; 3 Equality of factor loading, factor variances/co-variances.

\section{Convergent validity of the ELES}

To examine convergent validity, Pearson's correlation coefficients were calculated with other instruments (see Table 4). The three ELES factors correlated positively and statistically significantly with the GHQ-28 subscales and with the scores on the HARS and HRSD scales. The highest correlations were between ELES submission and GHQ-28 severe depression $(r=.390)$, and devaluation and severe depression $(r=.371)$, while the lowest correlations were threat and anxiety $(r=.185)$ and GHQ-28 insomnia and threat and social dysfunction $(r=.140)$ on the GHQ-28.

\section{Discriminant validity of the ELES}

As the ELES scale factors were significantly correlated with each other $(p<.01)$ : submission-threat, .718; submission-devaluation, .608; threat-devaluation, .592, the three factors representing differentiated constructs were verified, since the confidence intervals did not contain 1: submissionthreat, .820-.940; submission-devaluation, .710-.830; threatdevaluation, .704-.876. 
Table 4. Correlations of ELES, GHQ-28 and HADS subscales.

\begin{tabular}{|c|c|c|c|c|c|c|}
\hline & SOM & $\mathrm{AN}$ & DS & DEP & $\mathrm{HA}$ & HD \\
\hline SUM & $.316^{* *}$ & $.306^{* *}$ & $.255^{* *}$ & $.390^{* *}$ & $.352^{* *}$ & $.344^{* *}$ \\
\hline AME & $.234^{* *}$ & $.185^{* *}$ & $.140^{*}$ & $.268^{* *}$ & $.300^{* *}$ & $.326^{* *}$ \\
\hline DES & $.257^{* *}$ & $.252^{* *}$ & $.257^{* *}$ & $.371^{* *}$ & $.329^{* *}$ & $.357^{* *}$ \\
\hline
\end{tabular}

\section{Reliability of the ELES}

Internal consistency of the ELES was analyzed with the ordinal alpha, which resulted in $\alpha=.86$ for submission, $\alpha=$ .81 for devaluation and $\alpha=.90$ for the threat factor. For temporal stability, test-retest correlation coefficients found were .90 over a period of one month for a sample of 292 participants $(78.8 \%$ women $), M=21.68$ years $(S D=4.68)$, range 18 to 56 years of age.

As a final summary, Table 5 shows the indices for the re- liability and convergent validity study of the instrument for the three-factor model. We found that the Combined Reliability (CR) values for submission, threat and devaluation were over .7, and therefore, the three factors have adequate internal consistency. Furthermore, the Average Variance Extracted (AVE) was over .5 for the threat and devaluation factors, while submission was slightly lower. Convergent validity found for threat and devaluation was therefore adequate with $C R>A V E, A V E>.05$ (Fornell \& Larcker, 1981).

Table 5. Validity and reliability coefficients of the three-factor ELES model.

\begin{tabular}{lccccc}
\hline & CR & AVE & MSV & $\begin{array}{c}\text { Reliability } \\
\text { CR }>.7\end{array}$ & $\begin{array}{c}\text { Convergent Reliability } \\
\text { CR }>\text { AVE, AVE }>.5\end{array}$ \\
\hline SUBMISSION & & & & $\checkmark$ & X \\
THREAT & .846 & .440 & .693 & $\checkmark$ & $\checkmark$ \\
DEVALUATION & .873 & .580 & .692 & $\checkmark$ & $\checkmark$ \\
\hline
\end{tabular}

\section{Calculation of the ROC curve}

The Receiver Operating Characteristic curve (ROC) was carried out for the whole sample and for the overall ELES score, taking the patient/control condition as the criterion. The results show that the area under the curve was $.756(p<$ $.0001)$, for a confidence interval (CI) of .705-.808, with a sensitivity of $70 \%$ and specificity of $71 \%$ for a cutoff point of 32.5 .

\section{Discussion}

The main purpose of this study was to adapt the Early Life Experiences Scale (ELES) to Spanish. Its factor structure was analyzed by cross-validation, convergent and discriminant validity indicators and by finding indicators of the instrument's reliability.

In the first place, our data confirm the factor structure of the original version by Gilbert et al. (2003) finding a similar model with the three factors, submission, threat and devaluation. This solution explained $66.31 \%$ of the variance. The results of the final model was comprised of the same number of items as in the original study. The final model consisted of seven items for the "submission" dimension, five items for the "threat" dimension and three for "devaluation". Therefore, as predicted, this replication of the factor structure shows ELES construct validity for these three factors. The analysis of measurement invariance showed that the factorial structure, the relationship between the items and their corresponding factor are invariant across gender, which shows that the ELES scale is a conceptually appropriate measure that does not generate skewed interpretation between men and women.

In the second place, results for convergent validity show relationships between the measures of depression and anxiety, especially for the submission and devaluation factors. The relationship between submission and presence of somatic symptoms and devaluation with social dysfunction are also strong, and all of them are theoretically coherent. Furthermore, the factors on the ELES scale were correlated with each other although discriminant validity was found.

The Spanish version of the ELES shows internal consistency, retest reliability and combined reliability indices adequate for use with guarantees similar to the original version. Finally, this instrument showed adequate sensitivity and specificity, considering the general patient condition, without differentiating diagnosis type.

This instrument may be very relevant in the study of early experiences and their role in psychopathological manifestations. For example, the threat factor has been related to dysmorphic body disorder (Veale \& Gilbert, 2014) and the presence of psychosis (Braehler, Harper, \& Gilbert, 2012). It has been reported that perceived loss of social position, shame, negative social identity and fear of stigma provide a pathway for social anxiety to appear in first psychotic episodes (Birchwood et al., 2007). The submission factor has been associated with the presence of psychosis and depression (Gilbert et al., 2001; 2002). The relationship between feelings of shame, perceived social Rank and rumination in depression was explored (Cheung et al., 2004), finding that 
social Rank and shame were highly related, that both correlated with rumination and that this partially mediated between shame and depression.

The submission and threat factor have also been associated with paranoia (Pinto-Gouveia et al., 2014), finding that paranoid thinking is closely related to social anxiety, in the context of interpretations of malevolence and when affiliative emotions are constrained (Gilbert, Boxall, Cheung, \& Irons, 2005; Mills, Gilbert, Bellew, McEwan, \& Gale, 2007). Differences in gender have been found, where women have higher scores in social anxiety, submissive behavior and low social power (Gilbert et al., 2005).

An association between submissive behavior and eating disorders has been found (Cardi et al., 2014), and it has been demonstrated that individuals with anorexia and bulimia nervosa seem to have higher levels of overall internal shame than patients with anxiety or depression (Grabhorn, Stenner, Kaufbold, Overbeck, \& Stangier, 2005).

Finally, the devaluation factor could have a relevant role in eating disorders. It has been reported that attitudes toward eating and anxiety about appearance are associated with valuations of inferiority, feelings of insecurity and fear of loss in interpersonal relations (Bellew, Gilbert, Mills, McEwan, \& Gale, 2006). It is also possible that this factor spans a more affiliative or emotional security dimension (in the sense of loss) and therefore more related to warmth (Gilbert et al., 2003).

Summarizing, the study of early interpersonal relationships with parents may require two approaches: on one hand, attachment may have to do with affiliative support in which persons are less vulnerable or recover more easily from problems if the bond is secure (Gilbert et al., 2007). This approach may have to do with the study of the need for protection, security or calmness (and therefore with participation of the opioid system and oxytocin). But this perspective is incomplete without studying the search for status, respect and resources (social ranking), where motivation for success and activation (and therefore related to monoamines such as dopamine), but which cause conditions of vulnerability when

\section{References}

Akin, A., Uysal, R., \& Çitemel, N. (2013). Çocukluk Deneyimleri Ölçeğinin Türkçeye uyarlanması. [The validity and reliability of Turkish version of the early life experiences scale]. Kastamonu Eğitim Dergisi, 21(4), 15411550. Retrieved from http://79.123.169.199/ojs/index.php/Kefdergi/ article/viewFile/55/43

Allan, S., \& Gilbert, P. (2002). Anger and anger expression in relation to perceptions of social rank, entrapment and depressive symptoms. Personality and Individual Differences, 32(3), 551-565. doi:10.1016/S0191-8869(01)00057-5

American Psychiatric Association (2000). Diagnostic and Statistical Manual of Mental Disorders, fourth edition, text revision (DSM-IV-TR). Washington DC: American Psychiatric Association.

Anderson, J. C., \& Gerbing, D. W. (1988). Structural equation modeling in practice: a review and recommended two-step approach. Psychological Bulletin, 103(3), 411-423. doi: 10.1037/0033-2909.103.3.411

Baumgartner, H., \& Homburg, C. (1996). Applications of structural equation modeling in marketing and consumer research: A review. status is threatened or defensive responses such as submissive behavior are required (Carvalho et al., 2013). These conditions may appear with parents or in other situations (e.g., bullying, abuse, etc.) (Cardi et al., 2014).

We conclude by affirming that the Spanish version of the ELES is a reliable, valid instrument for evaluating the memory of threat and subordination perceived during childhood in family relations and can be useful in constructing explanatory models in the study of various psychopathological manifestations. On the other hand, the analysis across gender invariance showed that the ELES scale can be used with men and women indistinctly. This output may allow to analyze carefully variables that can be relevant for the gender in terms of the relationships with the progenitors, for example, in conditions of abuse without the gender skew in the measuring tool itself. In the future it would be of interest to widen the studies on early experiences and the various emotional states in an attempt to establish predictive and mediation models, as well as part of evaluation prior to application of Compassion Focused Therapy (Gilbert, 2014), used in various psychological alterations.

This study had some limitations which should be kept in mind. First, it is a cross-sectional study, and therefore, with no follow-up of participants. The self-report measures used involve sources of error such as response tendencies, social desirability or memory distortion, as the farther back in time the information requested of the subject is, the greater the likelihood of forgetting. Certain emotional alterations, such as depressive or dissociative states, could also lead to memory alterations and biases. Therefore, as the ELES is a test which evaluates family relationships, including the perception of what they were like in the past, it would be recommendable to include controls for the variables that could alter memory.

Finally, it is of interest to be able to study the psychometric properties of the ELES with larger specific samples of the clinical population, which enable a factor analysis to find out whether the underlying three-factor structure remains in different subgroups of clinical subjects.
International Journal of Research in Marketing, 13 (2), 139-161. doi:10.1016/0167-8116(95)00038-0

Bellew, R., Gilbert, P., Mills, A., McEwan, K., \& Gale, C. (2006). Eating attitudes and striving to avoid inferiority. Eating Disorders, 14(4), 313322. doi:10.1080/10640260600796242

Birchwood, M., Meaden, A., Trower, P., Gilbert, P., \& Plaistow, J. (2000). The power and omnipotence of voices: Subordination and entrapment by voices and significant others. Psychological Medicine, 30(2), 337-344. doi: 10.1017/S0033291799001828

Birchwood, M., Trower, P., Brunet, K., Gilbert, P., Iqbal, Z., \& Jackson, C. (2007). Social anxiety and the shame of psychosis: A study in first episode psychosis. Behaviour Research and Therapy, 45(5), 1025-1037. doi:10.1016/j.brat.2006.07.011

Bowlby, J. (1980). Attachment and loss: Loss, sadness and depression (Vol. 3). New York: Basic Books.

Braehler, C., Harper, J., \& Gilbert, P. (2012). Compassion Focused Group Therapy for recovery after psychosis. In C. Steel (Ed.), CBT for 
Schizophrenia: Evidence-based interventions and future directions (pp. 236-266). Chichester, West Sussex, UK: John Wiley \& Sons.

Cardi, V., Di Matteo, R., Gilbert, P., \& Treasure, J. (2014). Rank perception and self-evaluation in eating disorders. International Journal of Eating Disorders, 47(5), 543-552. doi:10.1002/eat.22261

Carvalho, S., Pinto-Gouveia, J., Pimentel, P., Maia, D., Gilbert, P., \& MotaPereira, J. (2013). Entrapment and defeat perceptions in depressive symptomatology: through an evolutionary approach. Psychiatry: Interpersonal and Biological Processes, 76(1), 53-67. doi:10.1521/psyc.2013.76.1.53

Cheung, M. S. P., Gilbert, P., \& Irons, C. (2004). An exploration of shame, social rank and rumination in relation to depression. Personality and Individual Differences, 36(5), 1143-1153. doi:10.1016/S01918869(03)00206-X

Cheung, G.W., \& Rensvold, R.B. (2002). Evaluating goodness-of-fi t indexes for testing measurement invariance. Structural Equation Modeling, 9(2), 233-255. doi:10.1207/s15328007sem0902_5

Cruddas, S., Gilbert, P., \& McEwan, K. (2012). The relationship between self-concealment and disclosure, early experiences, attachment, and social comparison. International Journal of Cognitive Therapy, 5(1), 28-37. doi:10.1521/ijct.2012.5.1.28

Curran, P. J., West, S. G., \& Finch, J. F. (1996). The Robustness of Test Statistics to Nonnormality and Specification Error in Confirmatory Factor Analysis. Psychological Methods, 1(1), 16-29.

Duarte, C., Matos, M., Stubbs, R. J., Gale, C., Morris, L., Gouveia, J. P., \& Gilbert, P. (2017). The impact of shame, self-criticism and social rank on eating behaviours in overweight and obese women participating in a weight management programme. PLoS ONE, 12(1), e0167571. doi:10.1371/journal.pone.0167571

Elosua, P., \& Zumbo, B. D. (2008). Reliability coefficients for ordinal response scales. Psicothema, 20(4), 896-901.

Fornell, C., \& Larcker, D. F. (1981). Evaluating structural equation models with unobservable variables and measurement error. Journal of Marketing Research, 18(1), 39-50. doi:10.2307/3151312

Gilbert, P. (2000). The relationship of shame, social anxiety and depression: The role of the evaluation of social rank. Clinical Psychology \& Psychotherapy, 7(3), 174-189. doi:10.1002/10990879(200007)7:3\%3C174::AID-CPP236\%3E3.0.CO;2-U

Gilbert, P. (2001a). Evolution and social anxiety: The role of attraction, social competition, and social hierarchies. Psychiatric Clinics of North America, 24(4), 723-751. doi: 10.1016/S0193-953X(05)70260-4

Gilbert, P. (2001b). Evolutionary approaches to psychopathology: The role of natural defences. Australian and New Zealand Journal of Psychiatry, 35(1), 17-27. doi: 10.1046/j.1440-1614.2001.00856.x

Gilbert, P. (2001c). Depression and stress: A biopsychosocial exploration of evolved functions and mechanisms. Stress, 4(2), 121-135. doi: $10.3109 / 10253890109115726$

Gilbert, P. (2014). The origins and nature of compassion focused therapy. British Journal of Clinical Psychology, 53(1), 6-41. doi: 10.1111/bjc.12043

Gilbert, P., \& Allan, S. (1998). The role of defeat and entrapment (arrested flight) in depression: an exploration of an evolutionary view. Psychological Medicine, 28(3), 585-598. doi: 10.1017/S0033291798006710

Gilbert, P., Allan, S., Brough, S., Melley, S., \& Miles, J. N. V. (2002). Relationship of anhedonia and anxiety to social rank, defeat and entrapment. Journal of Affective Disorders, 71(1-3), 141-151. doi:10.1016/S0165-0327(01)00392-5

Gilbert, P., Birchwood, M., Gilbert, J., Trower, P., Hay, J., Murray, B.,... Miles, J.N.V. (2001). An exploration of evolved mental mechanisms for dominant and subordinate behaviour in relation to auditory hallucinations in schizophrenia and critical thoughts in depression. Psychological Medicine, 31(6), 1117-1127. doi: 10.1017/S0033291701004093

Gilbert, P., Boxall, M., Cheung, M., \& Irons, C. (2005). The relation of paranoid ideation and social anxiety in a mixed clinical population. Clinical Psychology \& Psychotherapy, 12(2), 124-133. doi:10.1002/cpp.438

Gilbert, P., Cheung, M. S.-P., Grandfield, T., Campey, F., \& Irons, C. (2003). Recall of threat and submissiveness in childhood: development of a new scale and its relationship with depression, social comparison and shame. Clinical Psychology \& Psychotherapy, 10(2), 108-115. doi:10.1002/cpp.359
Gilbert, P., McEwan, K., Hay, J., Irons, C., \& Cheung, M. (2007). Social rank and attachment in people with a bipolar disorder. Clinical Psychology and Psychotherapy, 14(1), 48-53. doi:10.1002/cpp.508

Goldberg, D.P. (1996). Goldberg General Health Questionnaire. Barcelona: Masson.

Grabhorn, R., Stenner, H., Kaufbold, J., Overbeck, G., \& Stangier, U. (2005). [Shame and social anxiety in anorexia and bulimia nervosa]. Zeitschrift Fur Psychosomatische Medirin Und Psychotherapie, 51(2), 179-193.

Gumley, A. I., Taylor, H. E. F., Schwannauer, M., \& MacBeth, A. (2014). A systematic review of attachment and psychosis: Measurement, construct validity and outcomes. Acta Psycbiatrica Scandinavica, 129(4), 257-274. doi:10.1111/acps.12172

Hollingshead, A. A. (1975). Five Factor Index of Social Position. New Haven, CT: Unpublished manuscript, Yale University.

Hu, L., \& Bentler, P. M. (1999). Cutoff criteria for fit indexes in covariance structure analysis: Conventional criteria versus new alternatives. Structural Equation Modeling: A Multidisciplinary Journal, 6(1), 1-55. doi:10.1080/10705519909540118

Lopes, B., \& Pinto-Gouveia, J. (2013). The relationship between childhood experiences of submissiveness, external shame and paranoia in a portuguese student sample. Progress in Psychology, 1(1), 1-10. Retrieved from

https://www.dora.dmu.ac.uk/bitstream/handle/2086/9820/PP011\% $\mathrm{E} 2 \% 80 \% 94 \% \mathrm{E} 2 \% 80 \% 94$. pdf?sequence $=1$ \&isAllowed $=\mathrm{y}$

Mills, A., Gilbert, P., Bellew, R., McEwan, K., \& Gale, C. (2007). Paranoid beliefs and self-criticism in students. Clinical Psychology and Psychotherapy, 14(5), 358-364. doi:10.1002/cpp.537

Muñiz, J., Elosua, P., \& Hambleton, R. K. (2013). Directrices para la traducción y adaptación de los tests: segunda edición. Psicothema, 25(2), 151-157. doi:10.7334/psicothema2013.24

Paetzold, R. L., Rholes, W. S., \& Kohn, J. L. (2015). Disorganized attachment in adulthood: Theory, measurement, and implications for romantic relationships. Review of General Psychology, 19(2), 146-156. doi:10.1037/gpr0000042

Paulik, G. (2012). The role of social schema in the experience of auditory hallucinations: A systematic review and a proposal for the inclusion of social schema in a cognitive behavioural model of voice hearing. Clinical Psychology and Psychotherapy, 19(6), 459-472. doi:10.1002/cpp.768

Pinto-Gouveia, J., Matos, M., Castilho, P., \& Xavier, A. (2014). Differences between depression and paranoia: The role of emotional memories, shame and subordination. Clinical Psychology and Psychotherapy, 21(1), 4961. doi:10.1002/cpp.1818

Pinto-Gouveia, J., Xavier, A., \& Cunha, M. (2016). Assessing early memories of threat and subordination: Confirmatory Factor Analysis of the Early Life Experiences Scale for adolescents. Journal of Child and Family Studies, 25(1), 54-64. doi:10.1007/s10826-015-0202-y

Quijada, Y., Kwapil, T. R., Tizón, J., Sheinbaum, T., \& Barrantes-Vidal, N. (2015). Impact of attachment style on the 1-year outcome of persons with an at-risk mental state for psychosis. Psychiatry Research, 228(3), 849-856. doi:10.1016/j.psychres.2015.05.013

Satici, S. A., Uysal, R., \& Akin, A. (2015). Early life experiences and selfcompassion: A structural equation modelling. Estudios de Psicología 36(2), 343-365. doi:10.1080/02109395.2015.1026123

Stevens, A., \& Price, J. (2000). Evolutionary Psychiatry. A new beginning (2nd ed.). Philadelphia, PA: Brunner-Routledge, Taylor \& Francis Group.

Tejero, A., Guimera, E., Farré J. M., \& Peri, J.M. (1986). Uso clínico del HADS (Hospital Anxiety and Depresión Scale) en población psiquiátrica: un estudio de sensibilidad, fiabilidad y validez. Revista Del Departamento de Psiquiatría Facultad de Medicina de Barcelona, 12, 233-238.

Valmaggia, L. R., Day, F., Garety, P., Freeman, D., Antley, A., Slater, M., ... McGuire, P. (2015). Social defeat predicts paranoid appraisals in people at high risk for psychosis. Schizophrenia Research, 168(1-2), 16-22. doi:10.1016/j.schres.2015.07.050

Veale, D., \& Gilbert, P. (2014). Body dysmorphic disorder: The functional and evolutionary context in phenomenology and a compassionate mind. Journal of Obsessive-Compulsive and Related Disorders, 3(2), 150-160. doi:10.1016/j.jocrd.2013.11.005

Wickham, S., Sitko, K., \& Bentall, R.P. (2015). Insecure attachment is associated with paranoia but not hallucinations in psychotic patients: The 
mediating role of negative self-esteem. Psychological Medicine, 45(7), 1495-1507. doi:10.1017/S0033291714002633

World Medical Association (2013). World Medical Association Declaration of Helsinki: Ethical principles for medical research involving human subjects. Journal of the American Medical Association, 310(20), 2191-2194. doi:10.1001/jama.2013.281053

Zigmond, A.S., \& Snaith, R.P. (1983). The Hospital Anxiety and Depression Scale. Acta Psycbiatrica Scandinavica, 67(6), 361-370. doi:10.1111/j.1600-0447.1983.tb09716.x 